\section{PROGRESS OF CANCER RESEARCH}

\author{
By DR. I. HIEGER \\ Chester Beatty Research Institute, Royal Cancer \\ Hospital, London
}

$\mathrm{T}$ $\mathrm{HE}$ composition of the twenty-fourth annual report of the British Empire Cancer Campaign (11 Grosvenor Crescent, London, S.W.1) shows that more research is being earried out on radiation therapy and theory, on carcinogenesis and on the biochemistry of eancer, than on any other branch of investigation pursued in the different centres of research supported by the Campaign.

It is of interest to see to what extent the subjects of study are representative of cancer research in other parts of the world by a comparison with the papers presented at the Fourth International Cancer Congress held at St. Louis last September. More than 75 per cent of the 260 odd papers given at the Congress were by scientific men from the United States, and it should be noted that their papers tended to be finished products, whereas the Campaign's report is rather more a statement of progress. Any such comparison is certainly liable to errors, for a number of reasons; nevertheless, the accompanying table will probably give an approximate idea of the relative precedence of the different lines of research with which the cancer problem is attacked.

Radiation therapy and theory ; use of radio-isotopes

Biochemistry of tumours and tumour Cancer Congress,
1947

bearers; nutrition; enzymes ;

Carcinogens, carcinogenesis

Chemotherapy diagnosis

Pathology and diagn

Hormones in cancer

Advances, clinical and surgical

Organisation (research and clinical)

Cytology and cytochemistry

Genetics and mutation

Tissue culture

Experimental pathology

Milk factor

Virus tumours

Social, racial and industrial cancer

Only a few of the interesting investigations described in the Campaign's report can be referred to in this review and some important work will unfortunately receive no mention.

It need scarcely be stated that much essential clinical investigation has been carried out at all medical centres, and an elaborate report of the Clinical Cancer Research Committee analyses nine hundred cases of cancer of the colon from every etiological, pathological and clinical angle.

The increasing prominence of physics in cancer research is chiefly due to developments in the tech. nique and theory of radiotherapy, in the use of radioactive isotopes, in the field of microscopy and in the application of physical chemistry to the study of carcinogens. The electronic characteristics and structural properties of carcinogens are now being used to explain why some compounds are carcinogenic and others not.

Haddow, at the Royal Cancer Hospital, recently arranged a meeting which Dr. Pullman from Paris was invited to address on a theory of electronic characteristics and carcinogenic activity of hydrocarbons. At this discussion, Dickens neatly hit the nail on the head by pointing out that the proof of any such theory would be its eapacity to predict the structural requirements for a 'super-carcinogen'.

If the emphasis at the present time is favouring the physicist, the organic chemist has found at least one sphere for new' synthetic work, that of chemotherapy, for another class of compounds has been introduced, the nitrogen mustards (for example, methyl-bis. ( $\beta$. chloroethyl) amine). The large number of papers on chemotherapy presented at the International Congress shows how intense is the search for some drug which will selectively destroy cancer cells. The interest in chemotherapy would probably be greater than that suggested by the table if the hormone investigations directed to hormone therapy were included.

Unfortunately, the extreme caution with which therapists are compelled to state their results has a decidedly chilling effect on the reader : for example, they are apt to speak of "some degree of amelioration, although the response is usually transient", or "every case of Hodgkin's disease has shown a good although temporary response to the drug", or "it is doubtful whether any retarding influence has been present in our cases". Research, or rather experimentation, in this field is still highly empirical, dare one say, haphazard; this is inevitable, for we still have very little knowledge of the vulnerability of cancer tissue.

Passey and his collaborators in Leeds are working with the transmissible milk factor for mouse mammary carcinoma, and have elegantly demonstrated by the electron microscope the presence of macro. molecular particles of definite size only in those tissues and secretions where the factor has been detected by the biological method. The further progress of these experiments will be awaited with much interest.

The mode of action of carcinogens is claiming more attention, to the satisfaction of those who see little purpose in the continued multiplication of new synthetic carcinogens. Selbie, at the Middlesex Hospital, and also the Edinburgh workers, have studied carcinogenesis by urethane on the lung of the mouse. They suggest that some tissue is stimulated to proliferation at a rate disturbing to tissue equili. brium, and that the urethane poisons a defence mechanism, allowing some other agent, perhaps a virus, to attack the cells and bring about malignancy. It may perhaps be objected that such an explanation scarcely does more than move the difficulties one step farther back.

Orr, at Leeds, comes to somewhat similar conclusions, namely, that the lung adenomata evoked by urethane supervene on an inflammatory process, and that mice, the lungs of which are particularly liable to pneumonic conditions when treated with urethane, are also more liable to lung tumours.

Dickens has succeeded in showing that saturated compounds can be dehydrogenated to the aromatic state by rabbit blood and by slices of muscle, kidney and spleen. The interest of this reaction lies in its bearing on a popular theory of cancer : that polycyclic saturated compounds in the body (cholesterol, sex hormones, bile acids) can by some error of meta. bolism be dehydrogenated to polycyclic aromatic carcinogens. Similar studies are being made by Shoppee at the Royal Cancer Hospital on the possibility of the conversion of $17 \alpha$-methyl- $D$-homoandrostane to carcinogenic methylchrysenes.

Berenblum has been working on the mechanism of the carcinogenic process with the aid of co- 
carcinogens, and also on the nature of the cancerproducing factors in addition to benzpyrene which are present in tar. This work, and the experiments of Woodhouse at Birmingham on petroleum, might give valuable information if an attempt were made on the part of a government inspectorate to assess the risks of using certain petroleum products. However, any such tests and recommendations would have little effect so long as industrial substances which are carcinogenic are not handled entirely by mechanized processes.

Glücksmann, at Cambridge, has treated mouse tissue with $X$ - and $\gamma$-rays in combination with cocarcinogens to see if the same synergistic effect can be observed as with chemical carcinogens. No such effect was detected, and histological examination showed profound differences between the papillomas induced by radiations and those induced by benzpyrene. Also at the Strangeways Laboratory, Lasnitzki has found that when an adenocarcinoma in mice is irradiated with X-rays, two-thirds of the injurious effect on the tumour is indirect and is brought about by changes in the still normal tissue surrounding the tumour. Thus the conclusions of Koller, arrived at by studies on irradiated tumours in human subjects, have been confirmed experimentally.

Peacock, at Glasgow, has investigated the cocarcinogenic action of croton oil added to overheated $\left(365^{\circ}\right)$ edible oil in feeding experiments on mice. He found that cancerous changes were brought about in the alimentary tract, although the proportion of positive results was much smaller than in experiments with carcinogenic hydrocarbons on skin or connective tissues. Similar tests on mice mutants produced by methylcholanthrene (Strong) which are particularly liable to gastric cancer might show facilitation of the effect of feeble carcinogens in the diet.

Pybus and Miller, at Newcastle, and also Carr, at Edinburgh, have been studying gene mutation produced by the administration of carcinogenic hydrocarbons to mice. The mutation theory has had an eventful career in cancer research. One of the first to propose that cancer cells are mutant forms of normal cells was Boveri, in $1912 \mathrm{X}$-rays and radium had long been known to be carcinogenic, when Muller in 1928 discovered that X-rays greatly increased the spontaneous mutation-rate in Drosophila. During the War, Auerbach et al. found mustard gas to be a potent mutagen; but unfortunately for the theory, Berenblum had shown that it prevents carcinogenesis by the hydrocarbons. Strong's discoveries have now been followed by a report from Demerec that benzpyrene and other carcinogenic compounds bring about mutations in Drosophila. He finds about 84 per cent correspondence between carcinogenic and mutagenic potentiality in a number of compounds given to the fruit fly in the form of a fine mist.

Sir Ernest Kennaway and Lady Kennaway are continuing their statistical work on the Registrar General's returns, and point out that in eighteen years the deaths from cancer of the lung in England and Wales have increased $16 \frac{1}{2}$ times in men (nearly 6,000 in 1945) and 8 times in women, although diagnosis must have been doubtful in some cases.

One of the most interesting conclusions in this investigation runs : "Cancer of the lung differs from that of the upper alimentary tract, larynx and skin in showing no inverse relation to ascent in the social scale (Stevenson, 1923). This suggests an airborne factor, as owing to the mixing action of the wind, there is less difference in the outdoor air breathed by different classes than in other social conditions such as food and cleanliness."

Hieger, in experiments on endogenic carcinogens, finds that these substances are concentrated in the cholesterol-rich fraction of tissues, not only from cancerous and non-cancerous human subjects, but also in commercial cholesterol obtained from cattle brain and spinal cord or from fish livers. Some recent results were described in this journal ("Carcinogenic Activity of Preparations Rich in Cholesterol", Nature, 160,270 ; 1947 ).

\section{OBITUARIES}

\section{Dr. Bernard S. Dyer}

The death of Dr. Bernard Shirley Dyer on February 12, in his ninety-second year, marks the passing of one of the very few remaining pioneers of agricultural chemistry of the late nineties.

Born in London on February 25, 1856, the son of J. A. Dyer, a well-known London journalist, Bernard Dyer was educated at the City of London School. On leaving school at the age of seventeen he became a pupil assistant in the laboratory of Dr. Augustus Voelcker, consulting chemist to the Royal Agricultural Society, spending three years there and later taking the University of London degree of B.Sc. In 1877, at the early age of twenty-one, he established his laboratory at 17 Great Tower Street, London, where he remained until the laboratory was destroyed in the 'blitz' of May 1941. Here, while engaged in building up a practice in agricultural and food chemistry, he devoted much time in his earlier years to the publication of a series of agricultural articles in the scientific and lay Press, and also undertook a very considerable amount of lecturing throughout the country. About this period he was appointed consulting chemist to the Devon Agricultural Society, and later to the Essex and Leicestershire Societies.

There can be little doubt that Bernard Dyer's training with Voelcker had led to a specialization in agricultural chemistry which determined his future trend and the major interest in his life. Year after year, papers were published dealing with field investigation work, and, in particular, with the use and application of fertilizers and the necessity for far larger amounts than was then customary in Britain. Then came some years of work on the vexed question of soil analysis as a means of indicating the availability of the mineral constituents of the soil. The suggestion had already been made by Sachs that plants extracted their mineral food from the soil by the solvent action of the root sap exuded from their root hairs, and Tollens and Stutzer had suggested the use of a 1 per cent solution of citric acid for the assessment of the relative 'availability' of phosphatic fertilizers. Bernard Dyer attacked the problem from this new angle. He first determined in his laboratory the root acidity of about a hundred plants, and found the average figure to be the equivalent of 0.9 per cent citric acid-a figure substantially that suggested by Tollens and Stutzer. He then, in 1889 , systematically analysed soil samples from twenty-two plots of Hoos Field, Rothamsted. The outcome of this work was the elaboration of the now well-known method of soil extraction using a 1 per cent citric acid solution. This was published in the Journal of the Chemical Society in 1894, and for this investigation the 